\title{
Osteoma of the Zygomatic Process of the Temporal Bone-A Rare Case Report
}

\author{
Manabendra Debnath, Biswajit Gogoi \\ Department of ENT, HAMM Hospital and Research Centre, Hojai , Assam, India
}

\begin{abstract}
Osteomas are the slow growing benign tumours of the lamellar bones. They are the most common benign neoplasm of nose and paranasal sinuses. But osteomas of the temporal bone are rare and that of the zygomatic process are very very rare. In this case, we present a 38 years old female patient with osteoma of the zygmatic process of the left temporal bone. The osteoma was excised under General anaesthesia and the excised specimen was send for histopathology examination. The report came out to be osteoid osteoma. In this article, we present the incidence and clinicopathological features of osteoma.
\end{abstract}

Keywords: osteoma, osteoid osteoma, exostoses

\section{Introduction}

Osteomas are benign tumours of mature lamellar bones. They are the most common benign neoplasm of nose and paranasal sinuses. While well documented in the external auditory canal, they are otherwise very rare in temporal bone. Osteomas of mastoid are rare and that of zygomatic process of the temporal bone are even rarer. The overall incidence of osteoma is low, affecting 0.01 to $0.04 \%$ of the population; osteomas comprise $12.1 \%$ of benign bone tumours and $2.9 \%$ of all bone tumours. As per the review literature available only 2 cases of osteoma of the zygomatic process of the temporal bone has been reported till date.

\section{Case report}

A 38 years old female presented with a slow growing swelling in the left pre-auricular region for last 3 years. There was no history of any trauma or infection. Neither there was any pain over the swelling nor there any earache. On examination, the swelling was about $2 \mathrm{~cm} \times 1.5 \mathrm{~cm} \times 2.5 \mathrm{~cm}$, non tender, stony hard, smooth with well defined margins. The overlying skin was normal in colour with no signs of inflammation and was non adherent to the swelling. The General, Systemic and rest of the ENTexaminations are within normal limit. The routine blood investigations are also within normal limit and USG abdomen reveals no significant finding. CT scan reveals a well definedhyperdenseexophytic lesion about $1.99 \mathrm{~cm} \times 1.46 \mathrm{~cm} \times 2.29 \mathrm{~cm}$ in its antero-posterior, transverse and craniocaudal dimensions respectively arising from the outer table of the zygomatic process of the left temporal bone suggestive of osteoma.
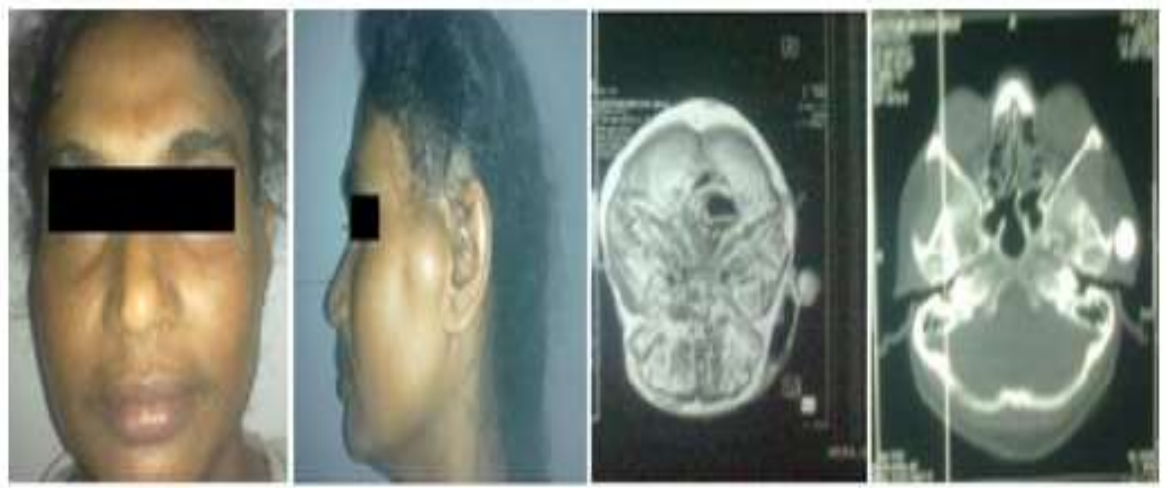

Figures :showing osteoma of the zygomatic process of the left temporal bone

The patient was then prepared for excision of the osteoma under General Anesthesia. A pre-auricular incision was made and the tumour was exposed adequately. The periosteum was elevated and then by using a chisel and hammer the tumour was removed and the base was then smoothened by using a diamond drill burr. The wound was then closed in layers. The tumour was then send for histopathology examination which came out to be osteoid osteoma. She had an uneventful post-operative period. She is now being followed up in our ENT opd regularly. 


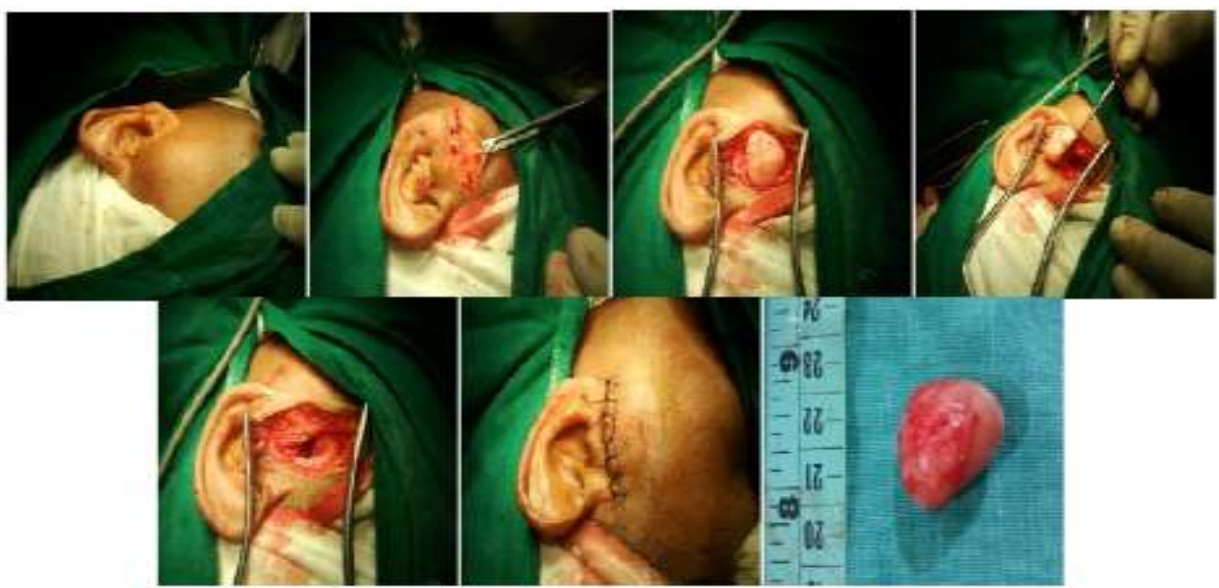

Figures: showing various steps in removal of the osteoma
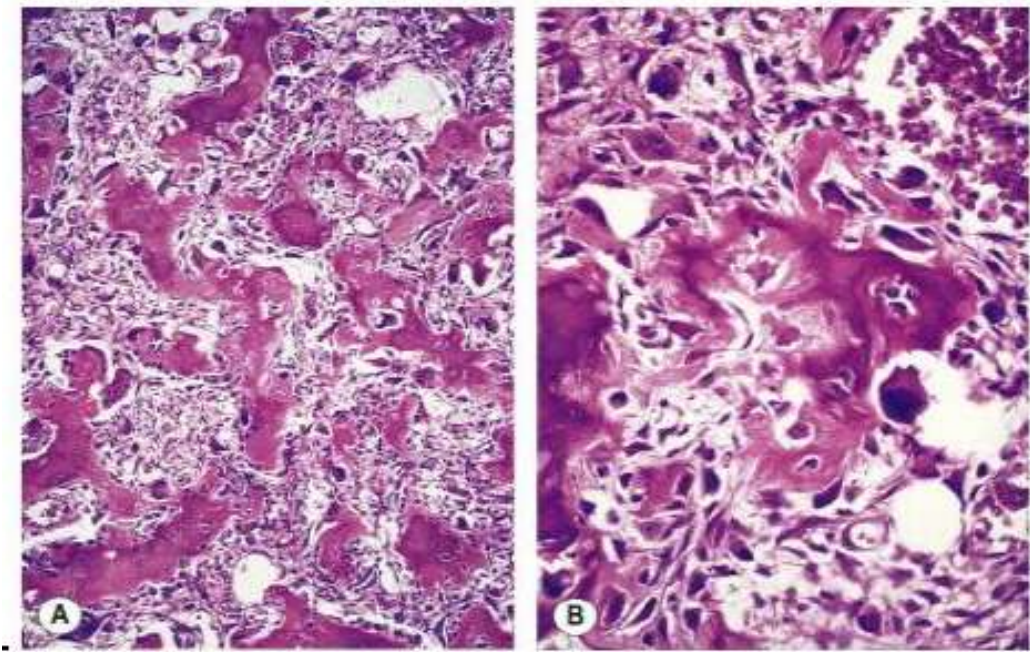

Fig. A. Histology of Osteoid osteoma in medium magnification(10X)

Fig.B. Histology of Osteoid osteoma in high magnification(40X)

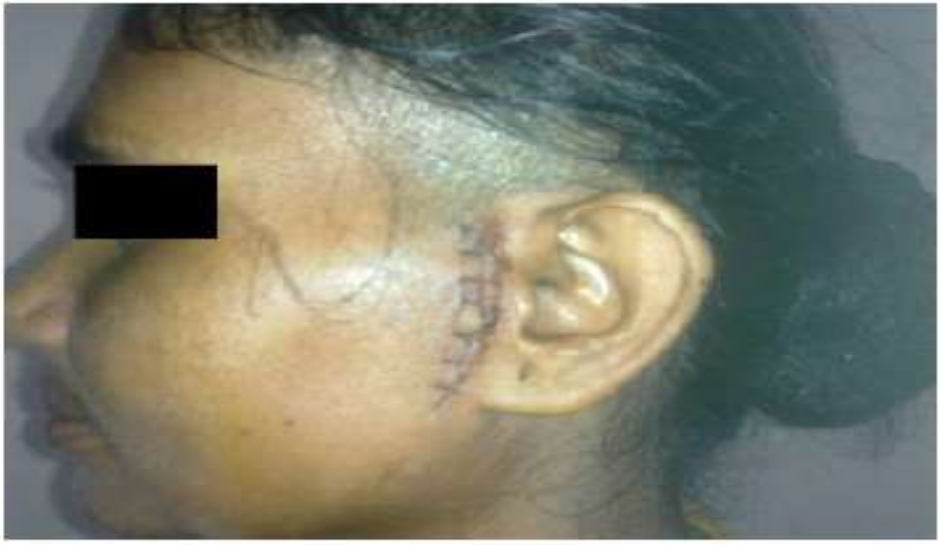

Patient during follow up in post-operative period

\section{Discussion}

Osteomas occur in all age gr oups but most commonly develop in the 30 to 60 year age group. Overall, osteomas are 3 times more common in women than men, but the type of osteoma known as osteoid osteoma usually oc curs in children and young adults and is 2 times more common in males than females. Black individuals seldom get osteomas.Osteomas are sometimes found in association with other diseases, such as polyps, fibromatous lesions of the connective tissue, or epidermal cysts (Gardner's syndrome). Although osteomas typically occur singly, multiple osteomas may occur in Gardner's syndrome, a diseasecharacterized by 
multiple internal polyps and other nonmalignant tumors. Multiple jaw osteomas raise the possibility of Gardener's syndrome (familial adenomatous polyposis). The osteomasmay be present for a decade or more before intestinal malignancy develops and their correct diagnosis can lead early recognition of the syndrome.The most common sites for osteoma development are the skull and facial bones, and osteomas are the most frequent benign tumors of the paranasal sinuses. These are common in the fronto-ethmoid region; however these are very rare in the temporal bone in which the external auditory canal is the predominant location. Extracanalicular osteomas of the temporal bone can present in the mastoid, squamous part of the temporal bone, internal auditory meatus and the middle ear. Osteomas can arise from the inner table of squamous and petrous part of the temporal bone resulting in brain compression and generalized epileptic seizure.Osteomas are the cause of sinus disease in 0.5-1 percent of patients. The frontal sinus is most frequently affected where obstructed drainage can result in large mucocoeles.Osteomata of mastoid are rare and that of zygomatic process of the temporal bone are even rarer. As per the review literature available only 2 cases of osteoma of the zygomatic process of the temporal bone has been reported till date.They are usually asymptomatic and treated mainly for cosmetic purposes. Lesions may arise on the surface of the bone presenting clinically as slow-growing, hard swellings, or be confined within the substance of the cancellous bone.

Radiologically, a sharply defined, densely radiopaque mass is typical. Osteomas resemble mature bone. Compact (ivory) osteomas consist of dense lamellae arranged in layers.Exostoses are more common than neoplasm. Most exostoses consist of lamella of compact bone, although larger ones may have a cancellous core. Extostoses are thought to be developmental or reactive lesions, whereas osteomas are true neoplasms.Compact osteomas have a wider base and are slow growing whereas spongy osteomas are more likely to be pedunculated and grow relatively faster. Osteomas are composed mainly of mature bone. Microscopically, osteomas are characterized by dense lamellae with organized Haversian canals. The intratrabecular stroma contains osteoblasts, fibroblasts, and giant cells, with no hematopoietic cells. Histologically there are three types of osteoma of the mastoid: osteoma compactum, osteoma cancellare, and osteoma cartilagineum. Clinically it is difficult to distinguish the type of osteoma because of the similarity of the symptoms and objective signs.

Exsostoses and osteomas are normally asymptomatic and only require treatment if they become problematic or cause cosmetic deformities. These lesions have no malignant potential and their growth can be exceedingly slow. Careful radiological evaluation is recommended for all but simplest cases. Surgery is usually the treatment of choice and in appropriate circumstances can be undertaken endoscopically or occasionally by radiofrequency ablation. In mastoid osteomas extending into the fallopian canal and bony labyrinth, complete excision is not indicated sincethere may be damage to these structures. Osteomas of the middle ear and inner ear are small and tend to remain small, so observation is preferred if there are no symptoms.

\section{Conclusion}

Osteoma of the zygomatic process of the temporal bone is indeed very very rare. Usually asymptomatic and the patient presents with cosmetic deformity. Proper history, physical and radiological examination like CT scan etc. is necessary to identify the location and extent of the osteoma. Excision of the tumour is not necessary if it is asymptomatic and done only for cosmetic purpose.

References

[1]. Larem, A. , Sheta, S. , Al-Qahtani, A. and Haidar, H. (2015) Stylomastoid Foramen

[2]. Osteoma: Unique Challenges for Appropriate Management. International Journal ofOtolaryngology and Head \& Neck Surgery,4, 277-281. doi:10.4236/ijohns.2015.44047.

[3]. Parelkar, K. , Thorawade, V. , Jagade, M. , Kar, R. , Pandare, M. , Nataraj, R. , Hanwate, R. , Attakil, A. and Kashide, R. (2014) Osteoma of Temporal Bone-A Rare Case report.

[4]. International Journal of Otolaryngology and Head \& Neck Surgery, 3, 252-258.doi: 10.4236/ijohns.2014.3504.

[5]. Bryan, E. and Kalina, P. (2013) Early Initial Diagnosis of Gardner Syndrome in a 12-YearOld Boy. Advances in Computed Tomography, 2, 1-3. doi: 10.4236/act.2013.21001

[6]. Aziz Mustafa. Osteoma of mastoid process obstructing external auditory canal: A casereport. Health .Vol.4 No.4, April 2012.

[7]. Kyung-Soo Nah, Osteomas of the craniofacial region, Imaging Science in Dentistry 2011; 41:107-13.

[8]. V Shikarwar, A Lavania\& R Saxena. Osteoma Temporal Bone- Rare case.

[9]. Nepalese Journal of ENT and Head and Neck Surgery. vol.2 No.1 issue 1(Jan-Jun 2011):25-26.

[10]. Tadashi Akamatsu, Rica Tanaka, Tsuyoshi Fukui,MuneoMiyasaka and Shinya Yamada. A Case of Mushroom shape temporal Bone Osteoma, Tokai J ExpClin Med. Vol. 34, No. 3, pp. 87-91, 2009.

[11]. Carlos Umberto Pereira1, Ricardo WathsonFeitosa de Carvalho, Annie Merielle Gomes de Almeida and Rafaela NunesDantas. Mastoid Osteoma. Consideration on Two Cases and Literature Review. International rchives of Otorhinolaringology July 2009 vol.13 No.3,642.

[12]. Furlaneto EC, Rocha JR and Heitz C. Osteoma of the zygomatic arch--report of a case.

[13]. Int J Oral Maxillofac Surg. 2004 Apr;33(3):310-1.

[14]. R Meher, B Gupta, I Singh and A Raj. Osteoma of Occipital bone. Indian Journal ofSurgery. Dec 2004 vol. 66 issue 6, $365-7$.

[15]. Rolf Wang-Norderud and RagabRadwanRagab. Osteoma of the Mandibular Condyloid Process.Scandinavian Journal of Plastic and Reconstructive Surgery and Hand Surgery.1976, Vol. 10, No. 1. 77-81.

[16]. Sheldon Mintz and Ines Velez. Osteoid osteoma of the zygoma report of an unusual case.The Journal of the American Dental Association .June 2007 vol. 138 no. 6 793-797. 
[17]. Shindo A, Honda C, Baba Y, Takashima S, Nagano bone with otitis media: a case study [Article in Mar;28(3):281-6.

[18]. T. Giant osteoma of the temporal Japanese]. No ShinkeiGeka. 2000

[19]. Stell\& Maran's Textbook of Head and Neck Surgery and Oncology, $5^{\text {th }}$ Edition -252.

[20]. Beale DJ and Phelps PD. Osteomas of the temporal bone: a report of three cases. ClinRadiol. 1987 Jan;38(1):67-9.

[21]. Gupta, O. P. and Samant, H. C. (1972), Osteoma of the mastoid. The Laryngoscope, 82: 172-176. 